\title{
Discrimination of As Sources in Greenhouse Soils in Northeast China Based on Multivariate Statistics
}

\author{
Peiying Yu ${ }^{1}$, Xubin Qian ${ }^{1}$, Shuang Cui ${ }^{1}$, Wenmiao Guo ${ }^{1}$, Jun Wang ${ }^{1, *}$ \\ 1 College of Chemistry, Chemical Engineering and Environmental Engineering, Liaoning Shihua University, Fushun 113001, China \\ * Corresponding author. E-mail addresses: mikewangjun@163.com (Jun Wang).
}

\begin{abstract}
The aims of this research were to determine the accumulation status of total As and discriminate the sources of As by the methods of multivariate statistics. Our results showed that total arsenic contents in top soils increased with cultivation duration, and had a significant positive correlation with cultivation years $\left(\mathrm{R}^{2}=0.5192, \mathrm{P}=0.009\right)$. Based on multivariate statistics, soil organic matters ( $\left.\mathrm{SOM}\right)$ and As in greenhouse soils may originate from the same source. It could be concluded that agrichemicals, especially chicken manures may cause As enrichment in greenhouse top soils.
\end{abstract}

\section{INTRODUCTION}

Arsenic (As) is a toxic element in the environment due to its well-known carcinogenicity. Drinking water and ingestion of contaminated food are primary As exposure pathways for human that pose an obvious threat to public health [1]. Sources of As contamination in agricultural systems mainly arise from exogenous inputs of organic compounds (e.g. poultry litter) containing As [2]. Past studies have revealed that As can accumulate in the food chain, and may lead to damage and alteration of human physiological functions because of its long biological half-lives for elimination [3, 4].

The area of greenhouse vegetable production (GVP) (except for small- and medium-scale arched shed) in China has exceeded 2.1 million hectare in 2016, and increased $9.2 \%$ compared to that of 2015 . GVP is a semienclosed artificial and energy-intensive production system, and fertilizers and pesticides containing heavy metals are applied excessively to meet the growing demand for leafy vegetables and maximize economic benefits. The intensive human activities are generating a negative impact on greenhouse environment and agricultural products. Excessive inputs of agrichemicals and huge amounts of irrigation have caused a series of environmental problems such as heavy metal contamination, soil hardening $[5,6]$. Some Chinese scientists have proved that heavy metals accumulated in soils of vegetable greenhouses in North China [3, 4]. However, few could afford an applicable and convenient method to find the source of heavy metals in greenhouse soil with a statistical method. Therefore, the objectives of this study have been to determine the accumulation status of total As and discriminate the sources of As by the methods of multivariate statistics.

\section{MATERIALS AND METHODS}

\subsection{Study area}

The research region is located in the west of Shenyang City in Liaoning province, covering with an enormous number of greenhouse facilities. The utilization of fertilizers is listed as follows: $80 \mathrm{t} \cdot \mathrm{hm}^{-2}$ of decaying chicken manure, $500 \mathrm{~kg} \cdot \mathrm{hm}^{-2}$ of carbamide or 1000 $\mathrm{kg} \cdot \mathrm{hm}^{-2}$ of ammonium sulphate $\left(\left(\mathrm{NH}_{4}\right)_{2} \mathrm{SO}_{4}\right)$, and $1000 \sim$ $1500 \mathrm{~kg} \cdot \mathrm{hm}^{-2}$ of diammonium phosphate $\left(\left(\mathrm{NH}_{4}\right)_{2} \mathrm{HPO}_{4}\right)$.

\subsection{Sampling and analysis}

Greenhouses of 1, 2, 3, 4, 5, and 6 years were selected, and the adjacent open field served as the control. Top soils $(0-20 \mathrm{~cm})$ were collected randomly. Soil samples were air dried, grounded and sieved to $<2.00 \mathrm{~mm}$ and $<0.149 \mathrm{~mm}$ fraction for determination of total As and soil physic-chemical properties. Total As was digested in aqua regia ( $\left.\mathrm{HCl}: \mathrm{HNO}_{3}=3: 1\right)$ [7] and measured by atomic fluorescence spectrophotometer (SuoKun, SK-2002). pH was determined from a 1:25 water-soil slurry using a $\mathrm{pH}$ meter [8]. Soil organic matters (SOM) were analysed by means of the Walkey-Black method [9]. Salt content in soils was determined by gravimetric method. Particle size distribution (texture) of the soil was determined using air-dried samples according to the pipette method $[10,11]$.

Statistical analysis was performed using SPSS 19.0.

\section{RESULTS}




\subsection{As accumulation in greenhouse soils}

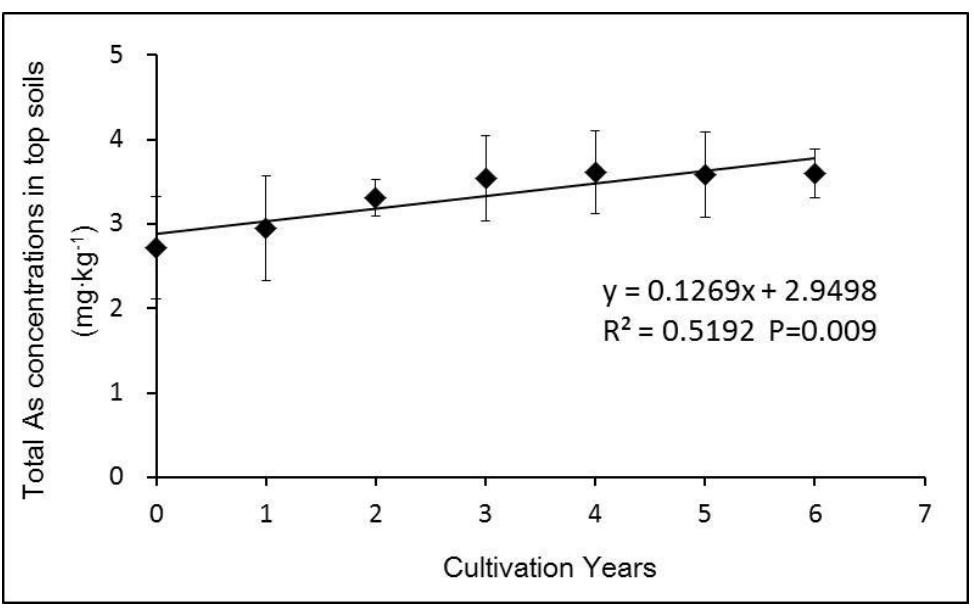

Figure 1. Total As contents in soils under greenhouse cultivation condition.

The error bars indicate the standard deviations.

As shown in Figure 1, total As contents in top soils increased with cultivation duration, and had a significant positive correlation with cultivation years $\left(\mathrm{R}^{2}=0.5192\right.$, $P=0.009)$. After cultivation for more than 3 years, the average of total As was between 3.5 and $3.6 \mathrm{mg} \cdot \mathrm{kg}^{-1}$. The concentrations of arsenic in 3-, 4-, 5- and 6-year greenhouses were all significantly higher $(\mathrm{P}<0.05)$ than those of the open field. Although As accumulated in greenhouse soils, As contamination did not appear in this zone according to National Soil Environmental Quality Standard I $\left(\mathrm{As} \leq 15 \mathrm{mg} \cdot \mathrm{kg}^{-1}\right)$.

\subsection{Pollutant source identification}

It is important to discriminate the natural and anthropogenic sources of heavy metals for remediation of soil contamination. Multivariate analysis (e.g. principle component analysis, cluster analysis, and correlation analysis) has been proved to be an effective method to identify the pollutant sources [12, 13]. As shown in Table 1, two factors explained $63.64 \%$ of all the total variance, demonstrating they were the most important factors. The first component (PC1) explaining $46.318 \%$ of the total variance was composed of As, soil organic matters (SOM), sand, silt, clay and cultivation years, therefore, demonstrates the anthropogenic sources of factors and indicates the impacts of agricultural activities and horticultural managements. The second component (PC2) explaining $17.324 \%$ of the total variance was composed of $\mathrm{pH}, \mathrm{SiO}_{2}, \mathrm{Al}_{2} \mathrm{O}_{3}$, and $\mathrm{Fe}_{2} \mathrm{O}_{3}$. The dendrogram of the elements showed three clusters of total As contents and soil properties (Figure 2). The first cluster included $\mathrm{As}$, $\mathrm{SOM}$, cultivation years, $\mathrm{pH}, \mathrm{Al}_{2} \mathrm{O}_{3}$, and $\mathrm{Fe}_{2} \mathrm{O}_{3}$, representing anthropogenic contamination sources. Cluster 2 included silt and clay, and cluster 3 comprised of sand and $\mathrm{SiO}_{2}$, representing natural sources such as rock weathering. Arsenic was positively correlated with SOM in greenhouse soils (Figure 2), manifesting that application of organic fertilizers would promote the accumulation of As.

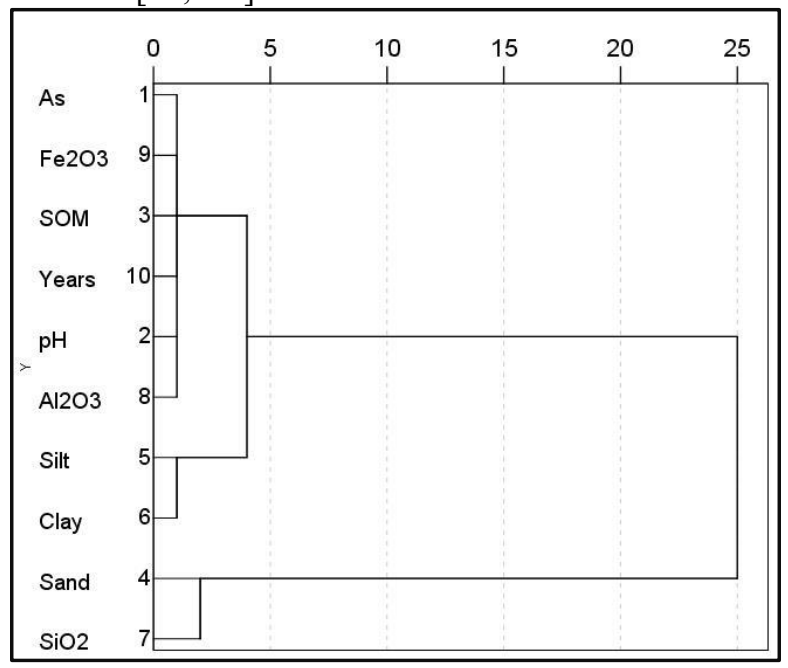

Figure 2. Dendrogram showing cluster of elements based on analysed variables 
Table 1 Rotated component matrix for total As contents and the physic-chemical properties of greenhouse vegetable soils

\begin{tabular}{|c|c|c|c|}
\hline \multicolumn{2}{|c|}{ Component initial eigenvalues } & \multirow[b]{2}{*}{$\%$ of Variance } & \multirow[b]{2}{*}{ Cumulative \% } \\
\hline Component & Total & & \\
\hline 1 & 4.632 & 46.318 & 46.318 \\
\hline 2 & 1.732 & 17.324 & 63.641 \\
\hline \multicolumn{4}{|c|}{ Component matrix (rotated) } \\
\hline \multirow[t]{2}{*}{ Variables } & & Component & \\
\hline & 1 & & 2 \\
\hline As & 0.449 & & 0.109 \\
\hline $\mathrm{pH}$ & -0.082 & & 0.549 \\
\hline SOM & 0.657 & & 0.372 \\
\hline Sand & -0.978 & & 0.019 \\
\hline Silt & 0.926 & & -0.102 \\
\hline Clay & 0.895 & & 0.095 \\
\hline $\mathrm{SiO}_{2}$ & 0.028 & & -0.780 \\
\hline $\mathrm{Al}_{2} \mathrm{O}_{3}$ & 0.518 & & 0.735 \\
\hline $\mathrm{Fe}_{2} \mathrm{O}_{3}$ & 0.522 & & 0.731 \\
\hline Cultivation Years & 0.498 & & 0.405 \\
\hline
\end{tabular}

Table 2 Correlation coefficients among total As and soil properties in greenhouse vegetable soils

\begin{tabular}{|c|c|c|c|c|c|c|c|c|c|c|}
\hline & T-As & $\mathrm{pH}$ & SOM & sand & silt & clay & $\mathrm{SiO}_{2}$ & $\mathrm{Al}_{2} \mathrm{O}_{3}$ & $\mathrm{Fe}_{2} \mathrm{O}_{3}$ & Years \\
\hline T-As & 1 & & & & & & & & & \\
\hline $\mathrm{pH}$ & -0.129 & 1 & & & & & & & & \\
\hline SOM & $0.357 *$ & 0.092 & 1 & & & & & & & \\
\hline Sand & -0.330 & -0.013 & $-0.588^{* *}$ & 1 & & & & & & \\
\hline Silt & 0.291 & -0.106 & $0.575^{* *}$ & $-0.951^{* *}$ & 1 & & & & & \\
\hline clay & 0.330 & 0.170 & $0.513^{* *}$ & $-0.911 * *$ & $0.737^{* *}$ & 1 & & & & \\
\hline $\mathrm{SiO}_{2}$ & -0.232 & -0.176 & $-0.377^{*}$ & -0.044 & 0.012 & 0.079 & 1 & & & \\
\hline $\mathrm{Al}_{2} \mathrm{O}_{3}$ & 0.210 & 0.290 & $0.487^{* *}$ & $-0.489^{* *}$ & $0.368^{*}$ & $0.574^{* *}$ & $-0.393^{*}$ & 1 & & \\
\hline $\mathrm{Fe}_{2} \mathrm{O}_{3}$ & 0.205 & 0.288 & $0.487 * *$ & $-0.494 * *$ & $0.371^{*}$ & $0.580^{* *}$ & $-0.389^{*}$ & $0.897 * *$ & 1 & \\
\hline Years & 0.305 & 0.051 & $0.439 *$ & $-0.436^{*}$ & $0.426^{*}$ & $0.380^{*}$ & $-0.405^{*}$ & $0.402 *$ & $0.402 *$ & 1 \\
\hline
\end{tabular}

T-Hg: total $\mathrm{Hg}$ contents

Significant levels: $* \alpha=0.05$, and $* * \alpha=0.01$

\section{DISCUSSIONS}

Sources of As contamination in agricultural soils primarily include industrial activities (mining and smelting) and arsenic compounds used for different purposes [2]. According to our previous investigation, there are no mining companies and manufacture factories in this zone, therefore industrial activities have little impact on As enrichment in greenhouse soils. SOM are significantly correlated with concentrations of heavy metals in greenhouse soils (Table 2), which is consistent with several articles [14, 15]. The first eigenvalues produced $46.318 \%$ of the total variance and had the highest weight for As contents, SOM and cultivation years (Table 1), and it was confirmed by the results of cluster analysis (Figure 1). It has been reported that SOM tended to increase with cultivation years due to green manure application, thus reflecting an impact of human activities and agricultural managements [16]. SOM is the main soil component to adsorb heavy metals, therefore, it can be concluded that As and SOM in greenhouse soils may originate from the same source. In the research region, approximately $80 \mathrm{t} \cdot \mathrm{hm}^{-2}$ of decaying chicken manure, $500 \mathrm{~kg} \cdot \mathrm{hm}^{-2}$ of carbamide or $1000 \mathrm{~kg} \cdot \mathrm{hm}^{-2}$ of ammonium sulphate $\left(\left(\mathrm{NH}_{4}\right)_{2} \mathrm{SO}_{4}\right)$, and $1000 \sim 1500$ $\mathrm{kg} \cdot \mathrm{hm}^{-2}$ of diammonium phosphate $\left(\left(\mathrm{NH}_{4}\right)_{2} \mathrm{SO}_{4}\right)$ are applied each year. Fertilizers, especially animal manures, have posed serious environmental problems due to the high concentrations of heavy metals [17]. The concentrations of As in animal manure-based composts are between 0.4 and $72 \mathrm{mg} \cdot \mathrm{kg}^{-1}$ under a national survey [18]. Arsenic can accumulate in chicken litter due to roxarsone (ROX) application as a feed additive [19]. So a mass of animal manure input is the primary source for As enrichment in greenhouse soils. 


\section{CONCLUSIONS}

Total arsenic concentrations in greenhouse soils did not exceed National Soil Environmental Quality Standard I $\left(\right.$ As $\leqslant 15 \mathrm{mg} \cdot \mathrm{kg}^{-1}$ ), and tended to increase with cultivation duration. According to multivariate analysis, As in top soils originated from the anthropogenic source due to intensive input of animal manures.

\section{ACKNOWLEDGEMENTS}

This work was financially supported by National Natural Science Foundation of China (41773093) and the National College Students' Innovative Entrepreneurial Training Plan (201710148000017).

\section{REFERENCES}

1. M.F. Naujokas, B. Anderson, H. Ahsan, H.V. Aposhian, J.H. Graziano, C. Thompson, W.A. Suk, Environ. Health. Perspect. 121 (2013) 295-302.

2. K.G. Sanjay, X. Chris Le, K. Cary, J.Z. Martin, S. Tariq, Sci. Total. Environ. 630(2018) 302-3-7.

3. D.C. Li, Z.P. Li, X. Zhou, T.L.Zhang, Rural EcoEnvironment 19, 3(2003) 38-41.

4. Y. Jiang, W.J. Liang, Y.G. Zhang, Chinese Journal of Soil Science 37, 6 (2006) 1184-11817.

5. B. Liu, Q. Huang, H. Cai, X. Guo, T. Wang, M. Gui, Food. Chem. 188(2015) 294-300.

6. Y. Chen, B. Huang, W. Hu, D.C. Weindorf, X. Liu, S. Niedermann, Sci. Total. Environ. 470-471(2014) 1140-1150.

7. L. Xu, T.Y. Wang, L. Wei, N. Kun, S.J. Liu, L. Wang, Y.L. Lu, China. J. Environ. Sci. 25(2013) 561-568.

8. A. Ariadne, K. Efstratios, B. Fotini, P. Vassiliki, K. Ioannis, T. Marini. J. Geochem. Explor. 9(2017) 113.

9. A. Walkley, I.A. Black, Soil Science 37(1934) 29-37.

10. G.W. Gee, J.W. Bauder, Methods of Soil Analysis: Part 11986.

11. C.V. Isabel, F.C. Gilberto, W. Beno, B. Lenka, S.F. Adão, Ecol. Indic. 74(2017) 182-190.

12. H. Zhang, Z.Z. Zheng, H. Yang, X.P. Ma, J.W. Wang, Soil 49, 4(2017) 819-827.

13. D. Hossein, F. Parvin, K. Behnam, Mar. Pollut. Bull. 115(2017) 401-411.

14. C. Gil, R. Bolida, Ramos, Chemosphere 55(2004) 1027-1034.

15. M. Chen, Q.M. Lena, W.G. Harris, J. Environ. Qual. 28(1999) 1173-1181.

16. S. Peeyush, L. Yael, R. Michael, M. Shlomit, S. Ibrahim, K. Arkady, V. Maggie, J.L. Guy, B.T. Asher, B. Mikhail, Geoderma. 305(2017) 197-207.
17. P. Alvarenga, C. Mourinha, M. Farto, T. Santos, P. Palma, J. Sengo, M.C. Morais, C. Cunha-Queda, Waste. Manage. 40(2015) 44-52.

18. X.P. Yang, Q. Li, Z. Tang, W.W. Zhang, G.H. Yu, Q.R. Shen, F.J. Zhao, Waste. Manage. 64(2017) 333-339.

19. L.X. Yao, L.X. Huang, Z.H. He, C.M. Zhou, W.S. Lu, C.H. Bai, Sci. Total. Environ. 566-567(2016) 1152-1158. 